\title{
Cost-Effectiveness of Anticoagulation in Patients with Nonvalvular Atrial Fibrillation with Edoxaban Compared to Warfarin in Germany
}

\author{
Martin Krejczy, ${ }^{1}$ Job Harenberg, ${ }^{1}$ Martin Wehling, \\ Konrad Obermann, ${ }^{2}$ and Gregory Y. H. Lip ${ }^{3}$ \\ ${ }^{1}$ Department of Clinical Pharmacology, Medical Faculty Mannheim, Ruprecht-Karls University Heidelberg, \\ Maybachstraße 14, 68169 Mannheim, Germany \\ ${ }^{2}$ Mannheim Institute of Public Health, Medical Faculty Mannheim, Ludolf-Krehl Straße, 68167 Mannheim, Germany \\ ${ }^{3}$ Centre for Cardiovascular Sciences, City Hospital, University of Birmingham, Birmingham B187QH, UK \\ Correspondence should be addressed to Job Harenberg; job.harenberg@medma.uni-heidelberg.de
}

Received 27 May 2014; Revised 17 September 2014; Accepted 18 September 2014

Academic Editor: Helen Mani

Copyright (C) 2015 Martin Krejczy et al. This is an open access article distributed under the Creative Commons Attribution License, which permits unrestricted use, distribution, and reproduction in any medium, provided the original work is properly cited.

\begin{abstract}
We compared the cost-utility analysis for edoxaban at both doses with that of dabigatran at both doses, rivaroxaban, and apixaban (non vitamin K antagonist oral anticoagulants, NOAC) in a German population. Data of clinical outcome events were taken from edoxaban's ENGAGE-AF, dabigatran's RE-LY, rivaroxaban's ROCKET, and apixaban's ARISTOTLE trials. The base-case analyses of a 65-year-old person with a CHADS2 score $>1$ gained 0.17 and 0.21 quality-adjusted life years over warfarin for $30 \mathrm{mg}$ od and $60 \mathrm{mg}$ od edoxaban, respectively. The incremental cost-effectiveness ratio was 50.000 and 68.000 euro per quality-adjusted life years for the higher and lower dose of edoxaban (Monte Carlo simulation). These findings were also similar to those for apixaban and more cost-effective than the other NOAC regimens. The current market costs for direct oral anticoagulants are high in relation to the quality of life gained from a German public health care insurance perspective. The willingness-to-pay threshold was lowest for $60 \mathrm{mg}$ edoxaban compared to all direct oral anticoagulants and for $30 \mathrm{mg}$ edoxaban compared to dabigatran and rivaroxaban.
\end{abstract}

\section{Introduction}

In a large prospective randomized double blind and double dummy study (ENGAGE-AF), once-daily dosing of the oral direct factor Xa inhibitor edoxaban $60 \mathrm{mg}$ (dose adjusted to $30 \mathrm{mg}$ ) was noninferior warfarin for the prevention of the primary endpoint of stroke and systemic embolic events in patients with nonvalvular atrial fibrillation (NVAF), when compared to warfarin with INR (international normalized ratio) adjusted to 2 to 3 ; edoxaban $60 \mathrm{mg}$ was also associated with a significantly lower rate of major bleeding and cardiovascular mortality [1]. Other nonvitamin $\mathrm{K}$ oral antagonist oral anticoagulants (NOAC, dabigatran, rivaroxaban, and apixaban) have proven to be superior or at least equivalent for stroke prevention and occurrence of severe bleeding complications in patients with NVAF compared to dose-adjusted warfarin. In the RE-LY trial $110 \mathrm{mg}$ bid dabigatran was noninferior and $150 \mathrm{mg}$ bid dabigatran was superior to dose-adjusted warfarin for prevention of stroke and systemic embolism and both doses resulted in less intracranial bleeding [2]. In the double blind ROCKET-AF trial patients on rivaroxaban $20 \mathrm{mg}$ od had reduced rates of stroke and systemic embolism and comparable major bleeding incidences compared to warfarin [3]. In the double blind ARISTOTLE trial, apixaban was associated with lower rates of strokes and major bleeding and reduced incidence of cardiovascular deaths compared to warfarin [4].

One of the main limitations for prescribing NOAC in real life is their higher daily price compared to warfarin. The pharmacoeconomic aspects of dabigatran, rivaroxaban, and 
apixaban were analysed for many countries. All have been demonstrated to be cost-effective in many countries for the health care system mainly based on the reduced incidence of major bleeding complications but also for some of the NOAC, due to a lower incidence of ischemic stroke and systemic embolism [5]. Related analyses include a willingness to pay, an incremental cost-effectiveness ratio (ICER) of a currency (euro, USD, or any other currency) per qualityadjusted life years (QALY) for dabigatran, rivaroxaban, or apixaban compared with warfarin. As the results of all these investigations were similar regarding the socioeconomic benefit of NOAC compared to warfarin, it was argued if these analyses have to be performed separately for every country. National guidelines for economic evaluation agree that a given country's unit costs should be applied to calculations of costs when adapting an analysis for local decision making [6]. As an example, lower prices for dabigatran in Europe compared with those in the USA were resulted in more favourable cost-effectiveness ratios despite smaller estimated gains in quality-adjusted survival [7]. Here we determined the cost-effectiveness of $60 \mathrm{mg}$ od and $30 \mathrm{mg}$ od edoxaban from a German payers perspective and compared the results with those obtained for the approved NOAC dabigatran (both doses $110 \mathrm{mg}$ bid and $150 \mathrm{mg}$ bid), rivaroxaban, and apixaban [5].

\section{Methods}

2.1. Markov Decision Model and Data Sources. We used the Markov decision model to analyse the QALYs, total costs (one-time costs for events, rehabilitation costs for inpatient and ambulatory care, inpatient medical treatment costs, and daily costs for drugs), and ICER based on the data of the ENGAGE-AF [1] study. The results were compared with our data previously derived from the RE-LY, ROCKET-AF, and ARISTOTLE trials [5] under a German health care insurance perspective. The following health states and outcome events were included: healthy with NVAF, transient ischemic attack, ischemic stroke (fatal, moderate to severe, and mild), haemorrhage (fatal, moderate to severe intracranial, mild intracranial, major noncerebral, and minor noncerebral), myocardial infarction (MI), recurrent and combined events, and cardiovascular mortality using the results from the ENGAGE-AF trial and costs for the German population [8] (Figure 1). Definitions of these events were taken from the ENGAGE-AF study [1]. Event probabilities were not included if they were not reported consistently across the studies (systemic embolism, pulmonary embolism, hemorrhagic stroke, and bleeding in other locations) (Table 1).

For the base-case analysis we used a hypothetical population cohort of patients with the starting age of 65 years with NVAF who were at increased risk for stroke (CHADS2-score $>1$ ) with no contraindications to anticoagulation as reported in the ENGAGE study [1]. Our results were expressed in quality-adjusted life years (QALY), 2012 euro, and incremental cost-effectiveness ratios (ICER: total costs $(€$, edoxaban) - total costs (€, warfarin)/QALY (edoxban) - QALY (warfarin)). We applied utilities and costs to each outcome yearly or event driven and discounted costs and benefits at 5\% annually $[9,10]$. A half cycle correction was done for each model, using a cycle length of 1 year. We quantified QALYs, risk for adverse events, and net cost for a time horizon of 20 years for the German population [11]. This time frame is used for CEA investigations taking well in account the much shorter treatment period of the studies from which the data are used (12).

2.2. Probability of Adverse Outcome Events and of Endpoints. The adverse outcome events and endpoints with the 95\% confidence intervals (CIs) were taken from the ENGAGE-AF study [1] and were found to be similar with those reported by Freeman et al. [12]. Intention to treat (ITT) values were taken for ischemic stroke, myocardial infarction, death from cardiovascular cause, and death from nonvascular cause and on-treatment values (OT) for bleeding events (minor bleeding, major bleeding, and ICH) for calculations in the sensitivity analyses (Table 1).

2.3. Severity of Stroke and Haemorrhage. Ischemic stroke was classified into fatal, moderate to severe, mild, and no neurologic deficit (4 categories) as reported [12]. A second mild ischemic stroke was defined to result in a moderate to severe ischemic stroke or death and a second moderate stroke in a severe ischemic stroke, reduced life quality, or death [13].

Haemorrhage was categorized into fatal, ICH with moderate to severe neurologic sequelae, ICH with no neurological deficit, major extracerebral haemorrhage, and minor extracerebral haemorrhage $[12,13]$. A moderate to severe ischemic stroke followed by an ICH was categorized into a moderate to severe neurologic outcome. Decrease of quality of life depended on the severity of outcome and resulted in different costs according to the German health care system [14].

2.4. Mortality Rates. The mortality rates (death from vascular cause and death from any other cause) were taken from the ENGAGE-AF study [1]. The annual rates for death from any other cause were taken from published German mortality tables [8].

2.5. Quality of Life Utilities. The quality-adjusted life years (QALY = survived life years adjusted for quality of life) [15] were calculated by multiplying the time spent within a health state with the corresponding utility value. The utility values for warfarin were taken from data on patients with NVAF who underwent time trade-off and standard gamble methods to estimate their quality of life $[12,16]$. All utility values were discounted in our model [17]. A utility of "1" represents a completely healthy status and a utility of "0" represents death. The mean utility for warfarin was $0.987[12,16,18]$. The utility for edoxaban was estimated as published for ximelagatran [12, $18]$, dabigatran, rivaroxaban, and apixaban $[5,12,13,16,18-$ 22].

2.6. Costs for Drugs and Outcome Events. One-time costs for most events were taken from the institute for payment regulations in German hospitals (Institut für Entgeltsystem 


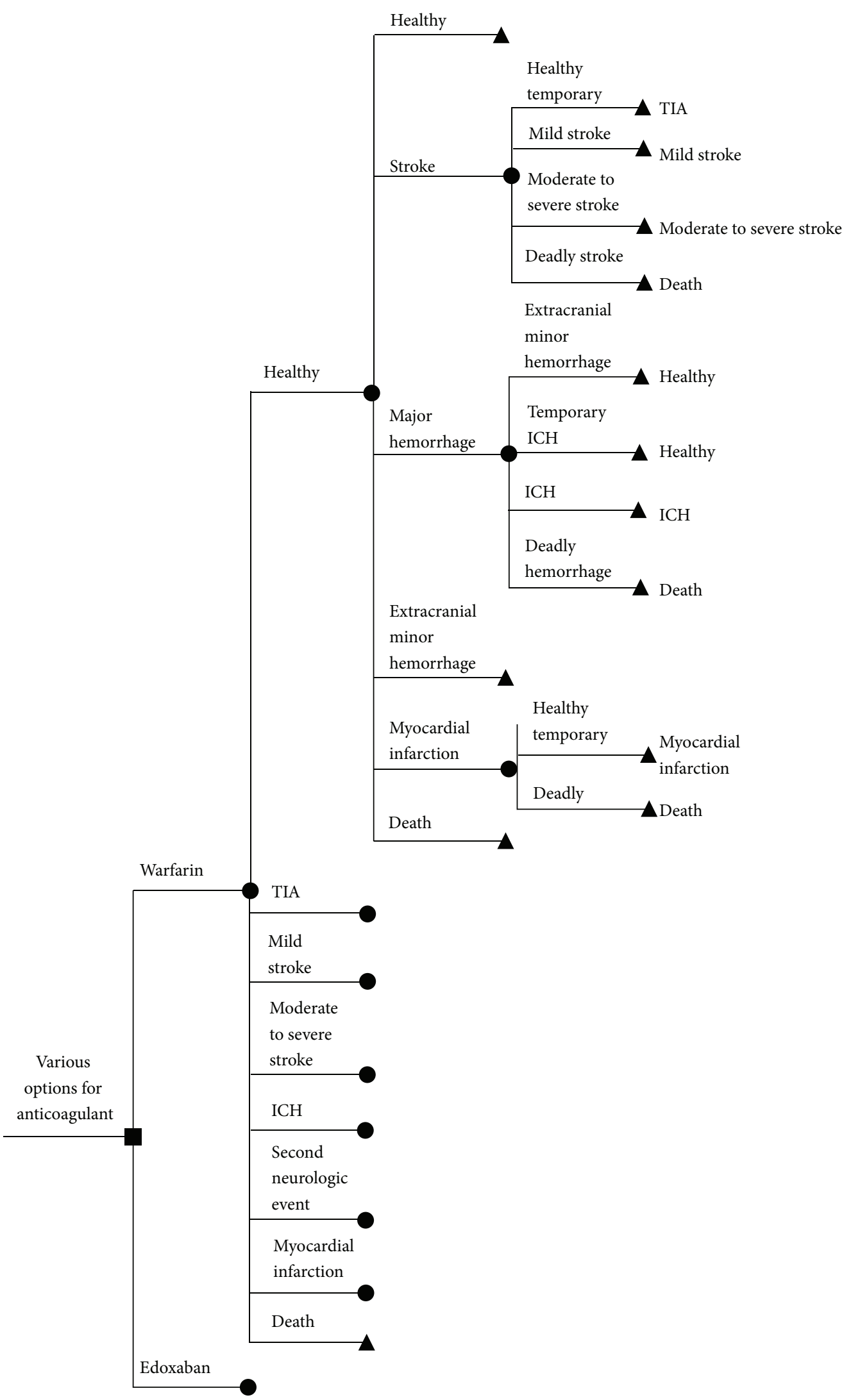

FIGURE 1: Outline of the Markov model for data of the ENGAGE-AF study. Here one dose of edoxaban is given as an example used in the Markov model. ICH intracerebral haemorrhage; TIA transient ischemic attack (modified from [5]). 


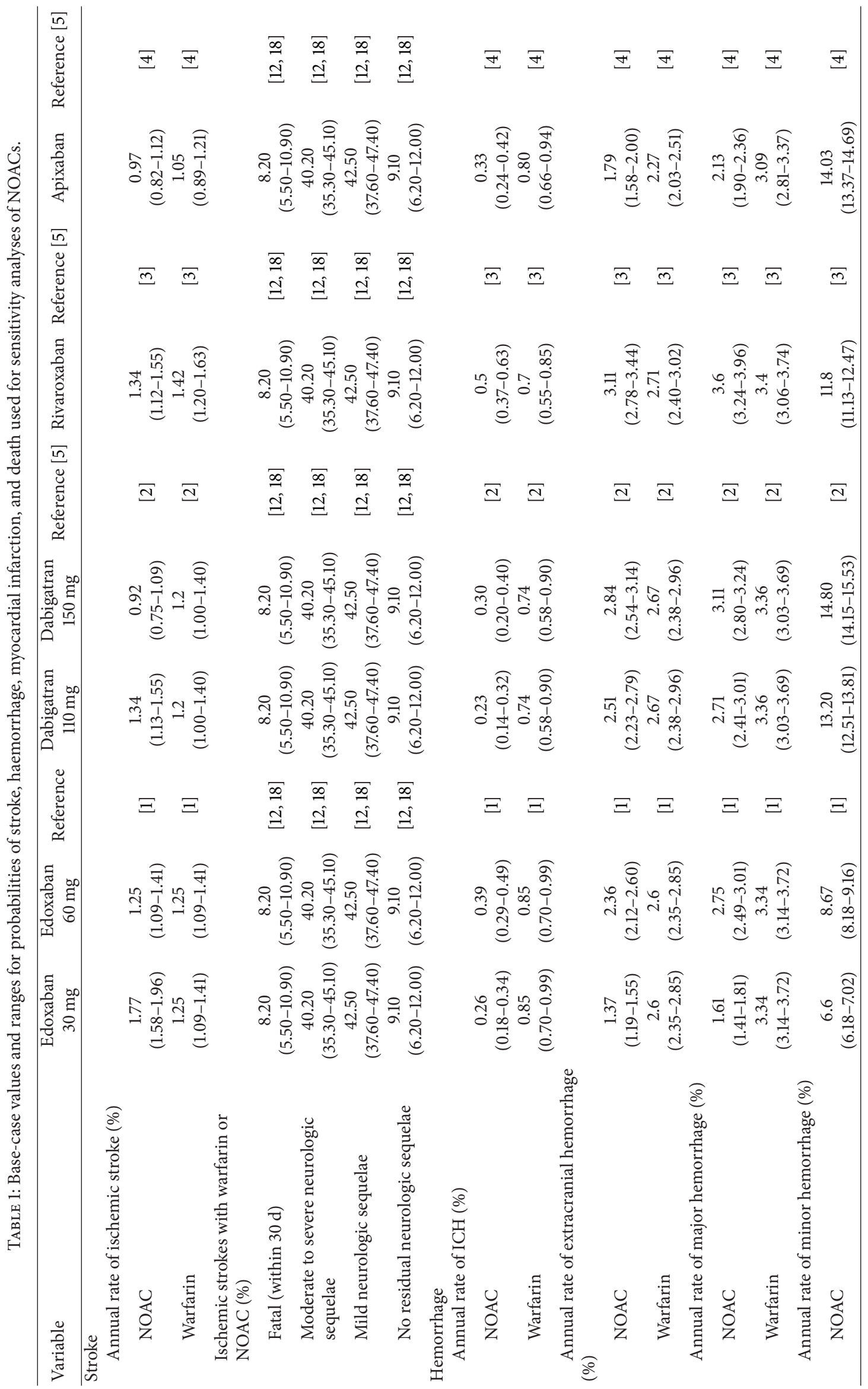




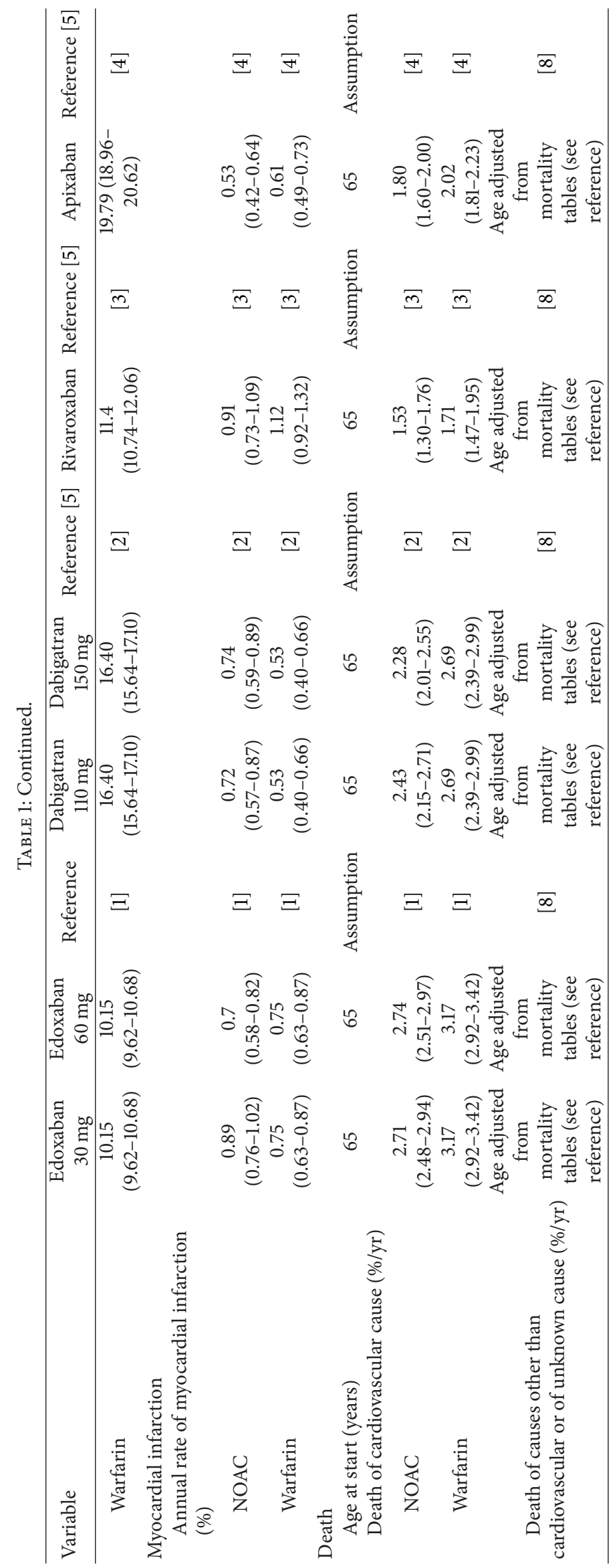


im Krankenhaus, InEK) which included German-diagnosis related groups (G-DRGs) [14] and were expressed in euro and reflected from the health care insurance perspective in Germany in 2012. Costs for bleeding events are not included in the G-DRGs and were taken from the literature [23]. Of note, our analysis did not include indirect costs and they were calculated over a time horizon of 20 years for the German population [11] with a discount of $5 \%(0 \%$ and $10 \%$ in the sensitivity analyses) per year $[9,10,24,25]$. Rehabilitation costs were included following ischemic strokes, ICH, and myocardial infraction, but not major bleedings without need for rehabilitation.

Cost for warfarin therapy, a mean of three-week interval for INR measurements with patient office visits, was set at $153 €$ annually $[26,27]$. The retail costs and daily costs for edoxaban according to costs of other NOACs (3.37 Euro per day) and phenprocoumon ( $0.20 €$ per day) were taken from pharmacies and the "red list" (German equivalent of “The Physicians' Desk Reference Manual” in USA, e.g.) [26]. Total costs for the drugs warfarin respected the event costs according to the InEK. These entries were used to examine the cost-effectiveness based on the event probabilities (Tables 1 and 3$)$.

2.7. Sensitivity Analyses. One-way sensitivity analyses of all variables were included in the decision models over their plausible ranges. Ranges for clinical events were derived from confidence intervals (CI) for event probabilities [1]. Medication costs for edoxaban and phenprocoumon were included as reported above. Two-way sensitivity analyses were performed for combinations of stroke and ICH using the values of warfarin [1].

2.8. Probabilistic Sensitivity Analysis. The Monte Carlo simulations (MCS) were made using random sampling and random distribution of variables for 10000 . Beta-distribution of the event probabilities was assumed for the calculation except for subcategories of stroke using Dirichlet distribution [12]. The Dirichlet distribution was chosen to show the probability of our subclassifications. Maximum and minimum ranges of costs for each adverse event were calculated using the German InEK and a gamma- and log normal distribution.

2.9. Statistical Methods. The models and analyses were created with TreeAge Pro 2013 and Microsoft Excel 2003.

\section{Results}

3.1. Base-Case Analysis, One-Way Sensitivity Analyses, and Two-Way Sensitivity Analysis. The calculated QALY, the total costs, and the ICER with edoxaban and warfarin are shown in Tables 2 and 3. For comparison the data derived from the outcome events of the RE-LY, ROCKET-AF, and ARISTOTLE trials are included as published [5]. The ICER for edoxaban $60 \mathrm{mg}$ was lower compared to edoxaban $30 \mathrm{mg}$ daily. Compared to the other NOAC regimens, edoxaban $60 \mathrm{mg}$ had the lowest ICER (Table 4). This difference is mainly due to the lower QALY of the warfarin group in the ENGAGE-AF study compared to the other studies.

The results of the one-way sensitivity analysis showed that the costs for edoxaban (both doses), the quality of life utilities, the treatment of ischemic stroke, and the treatment of major and intracerebral bleeding complications were important values in our model. Edoxaban and apixaban thus were most cost-effective compared to the other NOAC $[5]$.

3.2. Two-Way Sensitivity Analyses. The two-way sensitivity analyses of key variables for varying risk rates for ischemic stroke and intracerebral haemorrhage showed that both doses of edoxaban were preferable as a therapy for combinations of moderate to high risks for ischemic stroke and high risk of intracerebral haemorrhage at a set willingness to pay of 50.000€ per QALY against INR-dose-adjusted warfarin. These findings were also similar to those for apixaban and more cost-effective than the other NOAC regimens [5]. Using the probabilistic sensitivity analysis (PSA) in the Monte Carlo simulation by varying all variables simultaneously resulted in a willingness-to-pay threshold (PSA ICER) of 52.000€ per QALY for edoxaban $60 \mathrm{mg}$ od and $69.600 €$ per QALY for edoxaban $30 \mathrm{mg}$ od (Table 4). A similar market price was assumed for edoxaban at both doses as for the other NOAC. These data were similar to the base-case results and similar to apixaban and lower than for rivaroxaban and dabigatran at both doses as reported earlier [5]. The analysis demonstrates the cost-effectiveness of both doses of edoxaban for prevention of cerebral and noncerebral embolic events in patients with nonvalvular AF. The ICERs are comparable to apixaban and lower compared to dabigatran at both doses and rivaroxaban, despite an almost identical daily price for all NOACs.

\subsection{Probabilistic Sensitivity Analyses: Monte Carlo Simulation.} The various willingness-to-pay thresholds were analysed by using the probabilistic sensitivity analysis (PSA) in the Monte Carlo simulation (MCS) and varying all variables simultaneously. As a result edoxaban $60 \mathrm{mg}$ od and edoxaban $30 \mathrm{mg}$ od were cost-effective at willingness-to-pay threshold of 52.000€ per QALY and 67.000€ per QALY higher (Figure 2). The results of the cost-effectiveness at willingness-to-pay thresholds for the other NOAC treatment regimens are shown for comparison at Krejczy et al. [5]. The PSA results were similar to the base-case results.

3.4. Subgroup Analyses. Total costs increased and the ICER decreased in a base-case analysis for a 65 - to 85-yearold cohort from the German public health care insurance perspective excluding a discount for costs and utility values.

The absolute numbers of QALY and total costs decreased when costs and utility values were discounted by $10 \%$. In the same time the ICER increased in a base-case data for a 65to 85 -year-old cohort from the German public health care insurance perspective. 


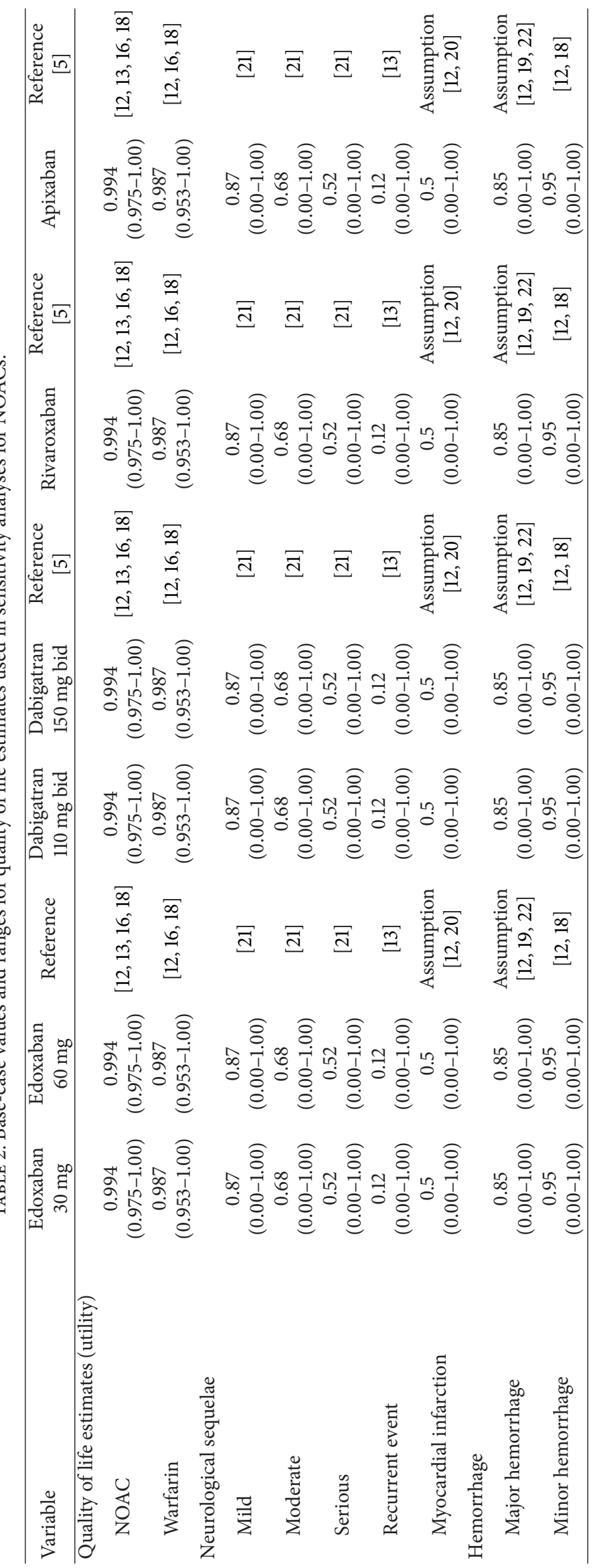




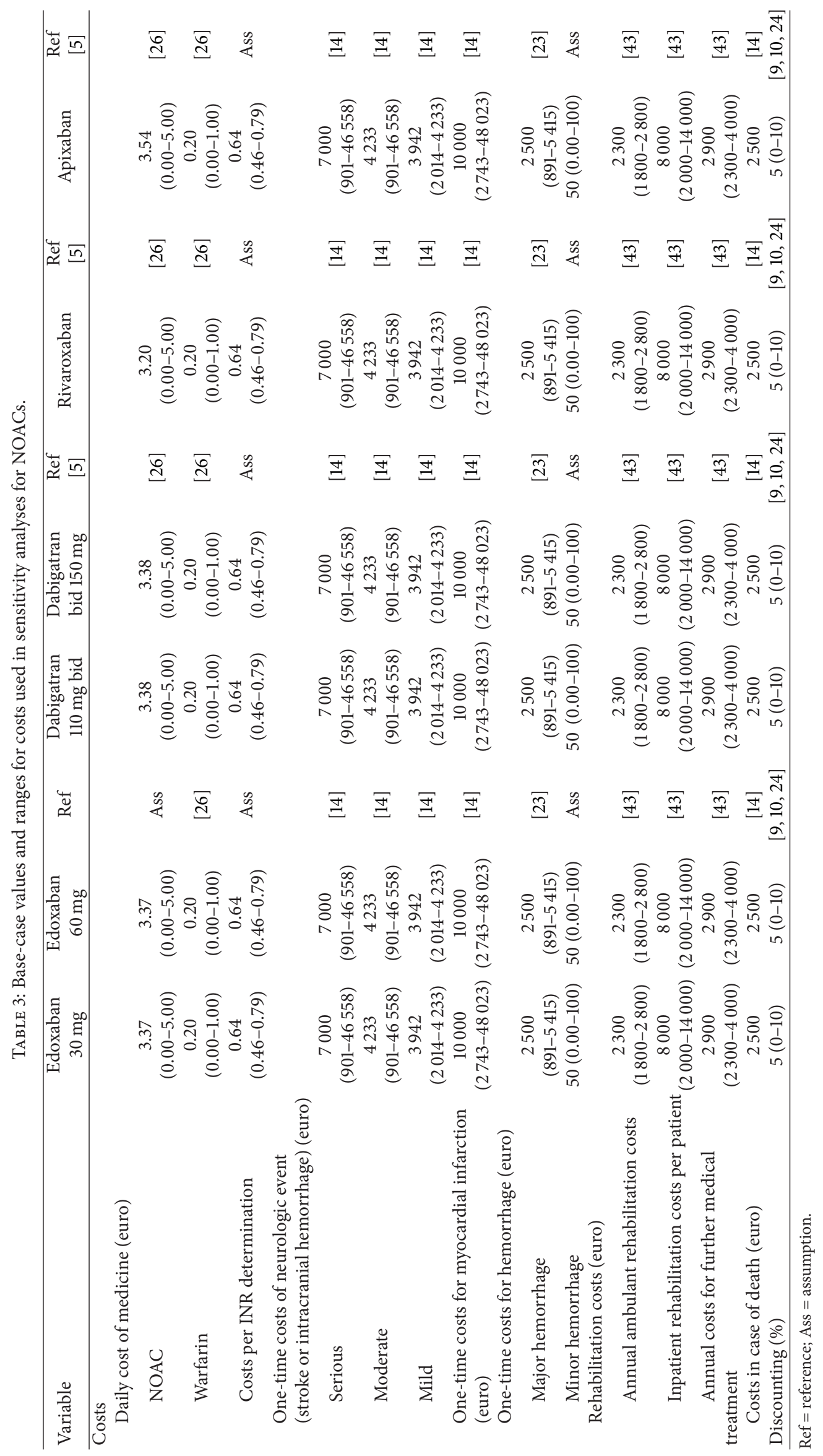


TABLE 4: Results of the base-case analysis for a 65-year-old population over a time horizon of 20 years from a German healthcare insurance perspective.

\begin{tabular}{|c|c|c|c|c|c|c|}
\hline Trial & Anticoagulant & QALY & $\begin{array}{c}\text { Total costs } \\
€\end{array}$ & $\begin{array}{c}\text { ICER } \\
€ / \mathrm{QALY}\end{array}$ & $\begin{array}{c}\text { Daily price } \\
€ / d\end{array}$ & $\begin{array}{c}\text { PSA ICER } \\
€ / Q A L Y\end{array}$ \\
\hline \multirow{4}{*}{ ENGAGE-AF } & Edoxaban $30 \mathrm{mg}$ od & 7.65 & 21052 & 68275 & 3.37 & 69600 \\
\hline & Warfarin & 7.48 & 9747 & & 0.20 & \\
\hline & Edoxaban $60 \mathrm{mg}$ od & 7.69 & 20157 & 50411 & 3.37 & 52000 \\
\hline & Warfarin & 7.48 & 9747 & & 0.20 & \\
\hline \multirow{4}{*}{ RE-LY [5] } & Dabigatran $110 \mathrm{mg}$ bid & 7.68 & 20048 & 294349 & 3.38 & 278000 \\
\hline & Warfarin & 7.64 & 7622 & & 0.20 & \\
\hline & Dabigatran $150 \mathrm{mg}$ bid & 7.71 & 19537 & 163184 & 3.38 & 174000 \\
\hline & Warfarin & 7.64 & 7622 & & 0.20 & \\
\hline \multirow{2}{*}{ ROCKET-AF [5] } & Rivaroxaban $20 \mathrm{mg}$ od & 7.67 & 19874 & 133926 & 3.20 & 130500 \\
\hline & Warfarin & 7.59 & 9069 & & 0.20 & \\
\hline \multirow{2}{*}{ ARISTOTLE [5] } & Apixaban $5 \mathrm{mg}$ bid & 7.75 & 19885 & 57245 & 3.54 & 55500 \\
\hline & Warfarin & 7.56 & 8915 & & 0.20 & \\
\hline
\end{tabular}

\section{Discussion}

The present study shows that the two dosage regimens of edoxaban $60 \mathrm{mg}$ od and edoxaban $30 \mathrm{mg}$ od are nearly costeffective bid for prevention of ischemic stroke and systemic embolic events in patients with NVAF based on the data of the ENGAGE-AF study based on a societal willingness to pay comparable to data from other countries. Comparing these data obtained with the other four treatment regimens with dabigatran $110 \mathrm{mg}$ bid, dabigatran $150 \mathrm{mg}$ bid (RE-LY study [2]), rivaroxaban $20 \mathrm{mg}$ od (ROCKET-AF study [3]), and apixaban $5 \mathrm{mg}$ (ARISTOTLE trial [4]) which are available in Germany and many other countries edoxaban $60 \mathrm{mg}$ was the most cost-effective followed by apixaban $5 \mathrm{mg}$ bid, edoxaban $30 \mathrm{mg}$ od, and the 3 remaining treatment regimens (Table 4). Of note these data were obtained using the same inputs into the Markov model based on the German insurance system. From the public health care insurance view, only edoxaban $60 \mathrm{mg}$ od treatment was nearly cost-effective at a hypothetical willingness-to-pay threshold of 50.000 EUR for patients at a moderate or higher risk of stroke (CHADS2-score $>1$ ) compared to INR-adjusted warfarin with current German market costs.

Similar analyses were reported for the two doses of dabigatran based on the health care costs and willingness to pay in USA [12, 13], Canada [28], United Kingdom $[29,30]$, Denmark [31], Sweden [32], and Portugal [33], for rivaroxaban in USA [34], for all three NOACs in USA [35], Canada [36], Germany [5], and Italy [37], and as a comparative analysis for dabigatran and rivaroxaban in Canada [38]. All analyses for dabigatran used the Markov model for calculation of the QALYs and ICERs and a one-way and two-way sensitivity analysis. In addition, we calculated these data for rivaroxaban and apixaban as well as for a certain range of daily costs for warfarin and daily costs of the NOACs for Germany. The cost data we used for the Markov model were comparable to those used in other countries $[12,28-$ $31,34]$.
Despite differences in model designs and structures of the cost-effectiveness analyses, it was mostly possible to replicate the results published by different authors in different countries like USA, UK, and Canada and identify variables responsible for differences between ICERs using a reference model approach [39]. All analyses for dabigatran used the Markov model for calculation of the QALYs and ICERs and a one-way and two-way sensitivity analysis. In addition, we calculated these data for rivaroxaban and apixaban as well as for a certain range of daily costs for warfarin and daily costs of the NOACs for Germany. The cost data we used for the Markov model were comparable to those used in other countries $[5,12,28-31,34]$. This enables a better interpretation of published findings by focusing attention on the assumptions underlying the key model features accounting for differences [39]. A real patient data analysis favoured dabigatran for stroke prophylaxis in patients with nonvalvular AF under the current hospital's perspective in a Hong Kong teaching hospital and provided a reference for further comparisons under patient and subsidization perspectives [40].

Limitations of pharmacoeconomic analyses include that they are not prespecified. Therefore the trials did not include patient-level documentation of medical resource use for estimates of total medical costs and administration of the EQ$5 \mathrm{D}$ for evaluation of health preferences (i.e., quality of life). The economic evaluation is more dependent on assumptions to calculate costs and the use of literature-based estimates of quality of life to generate QALYs [7]. Other limitations include differences between the studies: open [2] versus double blind study design $[1,3,4]$, age, gender, creatinine clearance, CHADS2 score, history of stroke, previous therapy with warfarin, time in therapeutic range (TTR) of the INR, other biographic data of patients, and reporting minor and nonmajor bleeding complications. It has to be considered that the TTR of the INR may be higher in the studies if anticoagulation clinics such as in The Netherlands or in Italy or self-monitoring systems are used. Therefore, the individual warfarin-control groups of every study have to 


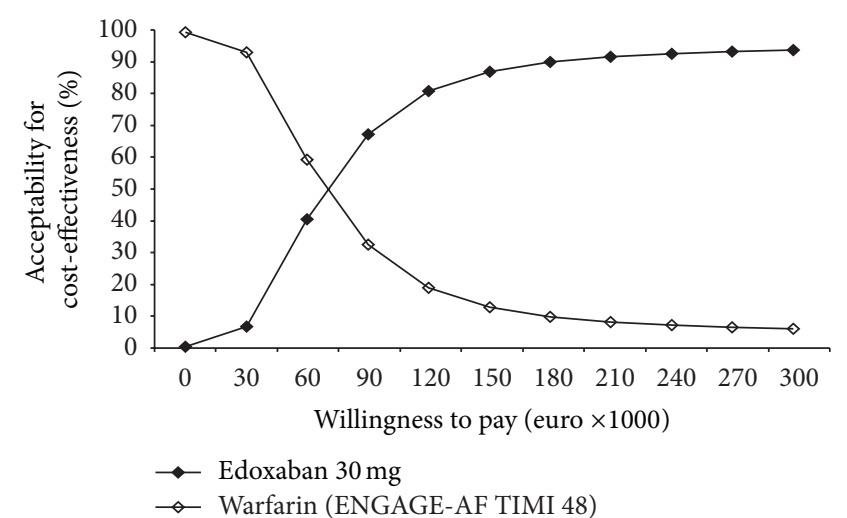

(a)

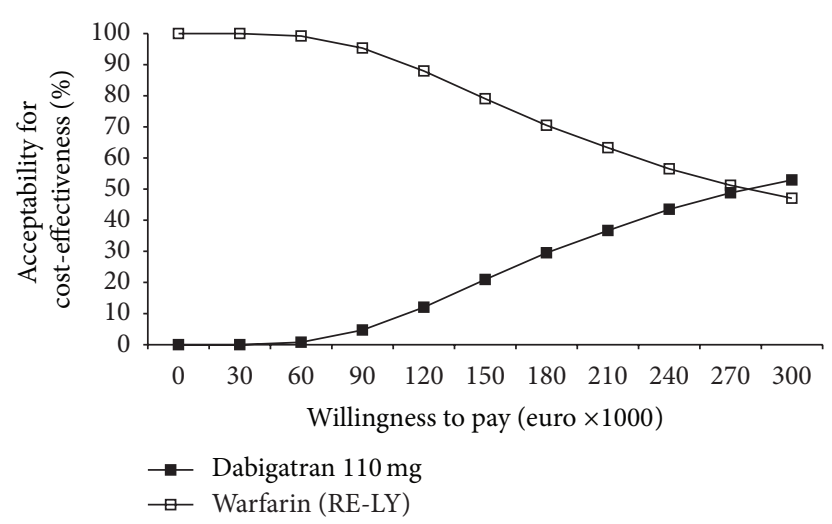

(c)

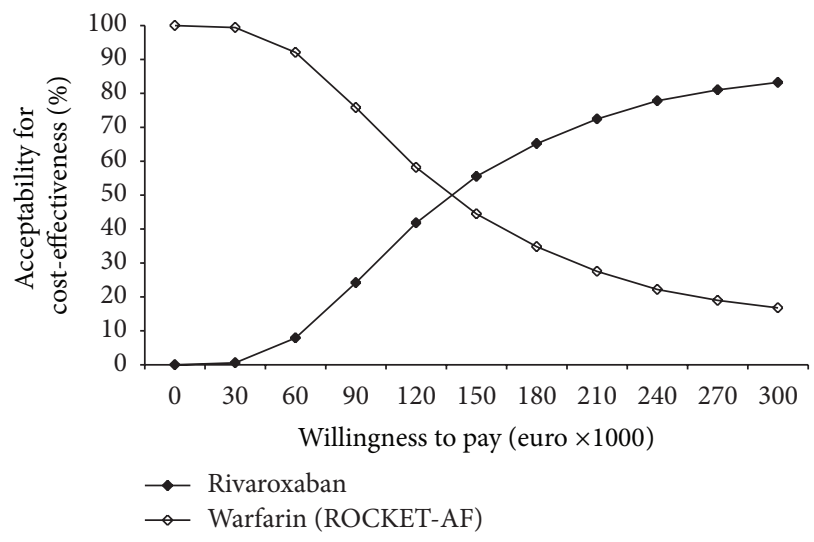

(e)

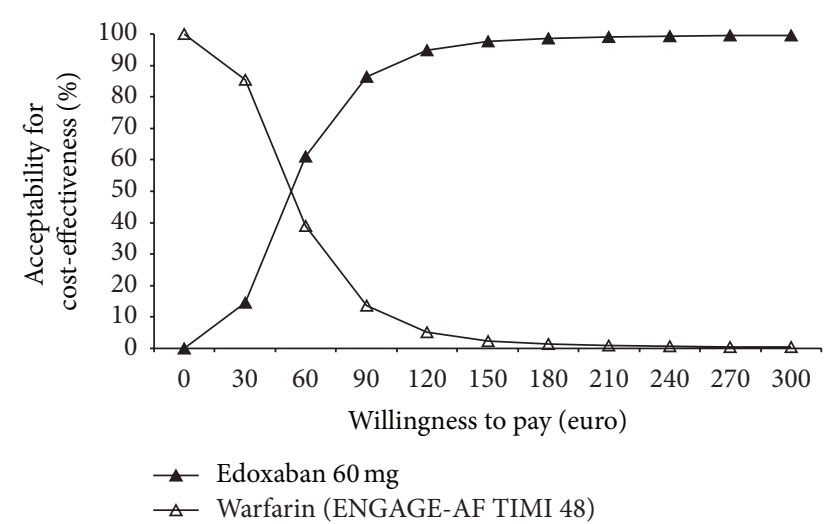

(b)

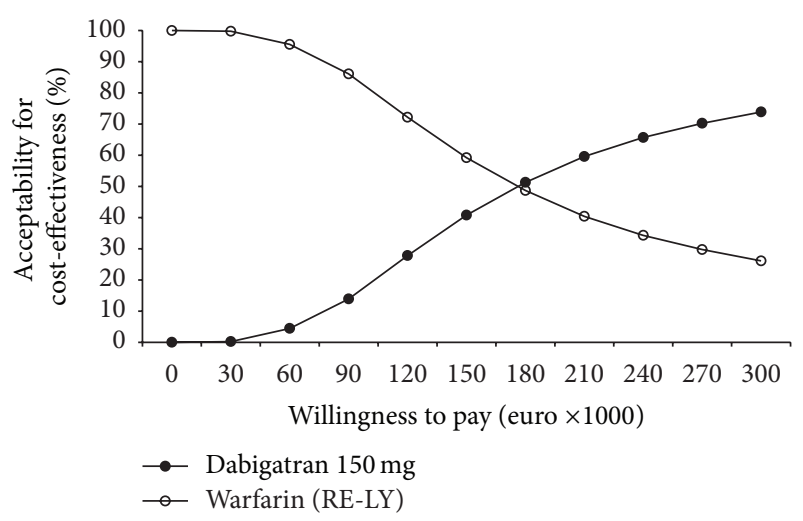

(d)

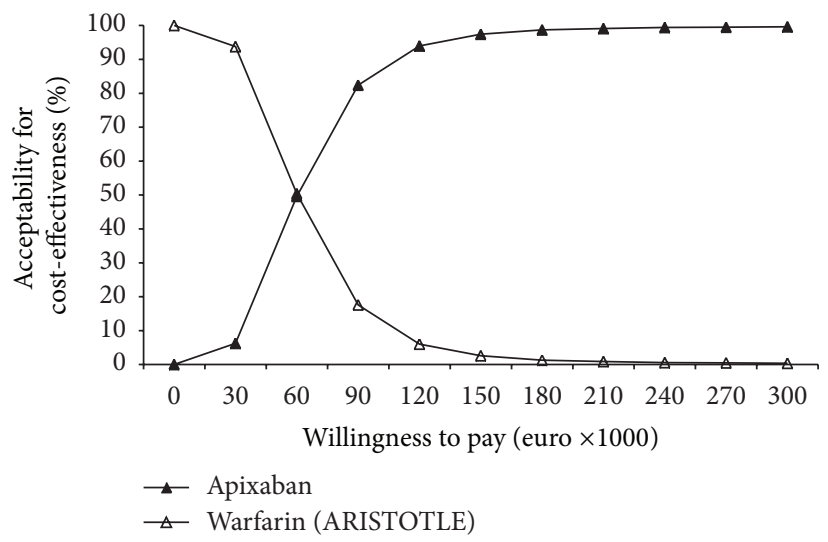

(f)

Figure 2: Monte Carlo simulation: acceptability curve for edoxaban $30 \mathrm{mg}$ od (a), edoxaban $60 \mathrm{mg}$ od (b), dabigatran $110 \mathrm{mg}$ bid (c), dabigatran $150 \mathrm{mg}$ bid (d), rivaroxaban $20 \mathrm{mg}$ od (e), and apixaban $5 \mathrm{mg}$ bid (f) compared to warfarin (results obtained from data of every NOAC study) with current market prices for a population starting with 65 years from a German health insurance perspective (reproduction of (c) to (f) with permission of the publisher of [5]).

be used for such investigations [41]. Other limitations of the study are the extrapolation from the shorter treatment period of the studies to a 20-year-time horizon for the costeffectiveness analysis, the fact that the willingness to pay may be set to a lower range of 20.000 to $30.000 €$, and the fact that in Germany no willingness-to-pay threshold exists for the health insurance system. This has to be respected for a comparison of the data across countries. The amount of willingness to pay depends substantially on the market price of the NOAC. It may be assumed that they will be reduced over time by the several economic fine-tunings. The lack of head-to-head trials makes it difficult to determine the most cost-effective agent [42]. Therefore we performed our costeffectiveness analysis strictly only using the results of the 
individual studies without indirect treatment comparisons and German mortality tables to decrease the variance of the results [5].

In conclusion, edoxaban in addition to apixaban may be regarded as the most cost-effective NOAC from a German public health care insurance perspective. The larger reduction in medical cost was mainly driven by reductions in the risks major bleeding events. Additional real life use of NOAC has to substantiate the present results for specific countries, which should be collected with a support of scientific and other independent organizations.

\section{Conflict of Interests}

Job Harenberg is an advisor or consultant for AstraZeneca, Bayer HealthCare, Boehringer Ingelheim, Bristol-Myers Squibb, Novartis, Pfizer, Polymedix, Roche Diagnostics, Sanofi-Aventis; speaker or a member of speakers bureau for AstraZeneca, Bayer HealthCare, Boehringer Ingelheim, Novartis, Sanofi-Aventis; Harenberg obtained grants for research from Bayer HealthCare; Boehringer Ingelheim, Bristol-Myers Squibb, Novartis, Pfizer, Sanofi-Aventis, Roche Diagnostics. Gregory Y. H. Lip is an advisor or consultant for Boehringer Ingelheim; Sanofi-Aventis; Bayer HealthCare; Merck \& Co.; Astellas; Portola; BIOTRONIK, Inc.; AstraZeneca; Bristol-Myers Squibb; Pfizer; Boehringer Ingelheim; Sanofi-Aventis; Bayer HealthCare; Merck \& Co.; Astellas; Bristol-Myers Squibb; Pfizer; Lip obtained grants for clinical research from Bayer HealthCare; Sanofi-Aventis. Martin Wehling was employed by AstraZeneca R\&D, Mölndal, as director of discovery medicine (translational medicine) from 2004 to 2006, while being on sabbatical leave from his professorship at the University of Heidelberg. After returning to this position in January 2007, lecturing and consulting for Novartis, Takeda, Roche, Pfizer, Bristol-Myers, DaichiiSankyo, Lilly, Leo-Pharma, Shire, and Novo-Nordisk. Martin Krejczy and Konrad Obermann do not have to declare conflict of interests.

\section{Authors' Contribution}

Conception and design of the work, acquisition of data, or analysis and interpretation of data were performed by Martin Krejczy and Job Harenberg. Drafting the paper or revising it critically for important intellectual content was done by Martin Krejczy, Job Harenberg, Martin Wehling, Konrad Obermann, and Gregory Y. H. Lip. Final approval of the version to be published was done by Martin Krejczy, Job Harenberg, Martin Wehling, Konrad Obermann, and Gregory Y. H. Lip.

\section{References}

[1] R. P. Giugliano, C. T. Ruff, E. Braunwald et al., "Edoxaban versus warfarin in patients with atrial fibrillation," The New England Journal of Medicine, vol. 369, pp. 2093-2104, 2013.

[2] S. J. Connolly, M. D. Ezekowitz, S. Yusuf et al., "Dabigatran versus warfarin in patients with atrial fibrillation," The New England Journal of Medicine, vol. 361, pp. 1139-1151, 2009.
[3] M. R. Patel, K. W. Mahaffey, J. Garg et al., "Rivaroxaban versus warfarin in nonvalvular atrial fibrillation," The New England Journal of Medicine, vol. 365, pp. 883-891, 2011.

[4] C. B. Granger, J. H. Alexander, J. J. McMurray et al., "Apixaban versus warfarin in patients with atrial fibrillation," The New England Journal of Medicine, vol. 365, pp. 981-992, 2011.

[5] M. Krejczy, J. Harenberg, S. Marx, K. Obermann, L. Frölich, and M. Wehling, "Comparison of cost-effectiveness of anticoagulation with dabigatran, rivaroxaban and apixaban in patients with non-valvular atrial fibrillation across countries," Journal of Thrombosis and Thrombolysis, vol. 37, no. 4, pp. 507-523, 2014.

[6] M. Drummond, M. Barbieri, J. Cook et al., "Transferability of economic evaluations across jurisdictions: ISPOR Good Research Practices Task Force report," Value in Health, vol. 12, pp. 409-418, 2009.

[7] S. D. Reed, "How country-specific should a country-specific cost-effectiveness analysis be?" European Heart Journal, vol. 34, pp. 166-167, 2013.

[8] J. W. Eikelboom, J. Hirsh, F. A. Spencer, T. P. Baglin, and J. I. Weitz, "Antiplatelet drugs: antithrombotic therapy and prevention of thrombosis, 9th ed: American College of Chest Physicians evidence-based clinical practice guidelines," Chest, vol. 141, no. 2, pp. e89S-el19S, 2012.

[9] M. C. Weinstein, J. E. Siegel, M. R. Gold, M. S. Kamlet, and L. B. Russell, "Recommendations of the panel on cost-effectiveness in health and medicine," The Journal of the American Medical Association, vol. 276, no. 15, pp. 1253-1258, 1996.

[10] H. Adam, M. Ahlert, F. Breyer et al., Dokumentation der Stellungnahmen zum "Entwurf einer Methodik für die Bewertung von Verhältnissen zwischen Nutzen und Kosten im System der deutschen gesetzlichen Krankenversicherung Version 2.0", Institut für Qualität und Wirtschaftlichkeit im Gesundheitswesen (IQWiG), 2009.

[11] G. Y. H. Lip, L. H. Rasmussen, S. B. Olsson et al., "Oral direct thrombin inhibitor AZD0837 for the prevention of stroke and systemic embolism in patients with non-valvular atrial fibrillation: a randomized dose-guiding, safety, and tolerability study of four doses of AZD0837 vs. vitamin K antagonists," European Heart Journal, vol. 30, no. 23, pp. 2897-2907, 2009.

[12] J. V. Freeman, R. P. Zhu, D. K. Owens et al., "Cost-effectiveness of dabigatran compared with warfarin for stroke prevention in atrial fibrillation," Annals of Internal Medicine, vol. 154, no. 1, pp. $1-11,2011$.

[13] S. V. Shah and B. F. Gage, "Cost-effectiveness of dabigatran for stroke prophylaxis in atrial fibrillation," Circulation, vol. 123, no. 22, pp. 2562-2570, 2011.

[14] InEK gGmbH, Hrsg., Vereinbarung zum Fallpauschalensystem für Krankenhäuser für das Jahr 2011, 2010, http://www.g-drg.de/ cms/G-DRG-System_2011/Fallpauschalen-Katalog/Fallpauschalen-Katalog_2011; abgerufen am 10.07.2011.

[15] M. F. Drummond, M. J. Sculpher, G. W. Torrance, B. J. O’Brien, and G. L. Stoddart, Eds., Methods for the Economic Evaluation of Health Care Programmes, Oxford University Press, New York, NY, USA, 3rd edition, 2005.

[16] B. F. Gage, A. B. Cardinalli, and D. K. Owens, "The effect of stroke and stroke prophylaxis with aspirin or warfarin on quality of life," Archives of Internal Medicine, vol. 156, no. 16, pp. 1829-1836, 1996.

[17] J. W. Hay, J. Smeeding, N. V. Carroll et al., "Good research practices for measuring drug costs in cost effectiveness analyses: Issues and recommendations: the ISPOR drug cost task force report. Part I," Value in Health, vol. 13, no. 1, pp. 3-7, 2010. 
[18] C. L. O’Brien and B. F. Gage, "Costs and effectiveness of ximelagatran for stroke prophylaxis in chronic atrial fibrillation," The Journal of the American Medical Association, vol. 293, no. 6, pp. 699-706, 2005.

[19] D. G. Fryback, E. J. Dasbach, R. Klein et al., "The Beaver Dam Health Outcomes Study: initial catalog of health-state quality factors," Medical Decision Making, vol. 13, no. 2, pp. 89-102, 1993.

[20] P. W. Sullivan and V. Ghushchyan, "Preference-based EQ5D index scores for chronic conditions in the United States," Medical Decision Making, vol. 26, no. 4, pp. 410-420, 2006.

[21] T. O. Tengs and T. H. Lin, "A meta-analysis of quality-of-life estimates for stroke," PharmacoEconomics, vol. 21, no. 3, pp. 191200, 2003.

[22] R. Thomson, D. Parkin, M. Eccles, M. Sudlow, and A. Robinson, "Decision analysis and guidelines for anticoagulant therapy to prevent stroke in patients with atrial fibrillation," The Lancet, vol. 355, no. 9208, pp. 956-962, 2000.

[23] A. Bufe, S. Frey, and S. Briswalter, "Durch Blutungen verursachte Kosten bei der Therapie des akuten Koronarsyndroms in Deutschland," Herz Kardiovaskuläre Erkrankungen, vol. 34, no. 6, pp. 479-484, 2009.

[24] Canadian Agency for Drugs and Technologies in Health, Guidelines for the Economic Evaluation of Health Technologies: Canada, Canadian Agency for Drugs and Technologies in Health, Ottawa, Canada, 3rd edition, 2006.

[25] J. M. Graf von der Schulenburg, W. Greiner, F. Jost et al., "German recommendations on health economic evaluationthird and updated version of the Hanover Consensus," Gesundheitsokonomie und Qualitatsmanagement, vol. 12, no. 5, pp. 285290, 2007.

[26] J.van Ryn, J. Stangier, S. Haertter et al., "Dabigatran etexilate-a novel, reversible, oral direct thrombin inhibitor: interpretation of coagulation assays and reversal of anticoagulant activity," Thrombosis and Haemostasis, vol. 103, no. 6, pp. 1116-1127, 2010.

[27] L. Hein, "Antithrombotika und Antihämorrhagika," in Arzneimittelverordnungs-Report 2011, pp. 421-439, Springer, Berlin, Germany, 2011.

[28] S. V. Sorensen, A. R. Kansal, S. Connolly et al., "Costeffectiveness of dabigatran etexilate for the prevention of stroke and systemic embolism in atrial fibrillation: a Canadian payer perspective," Thrombosis and Haemostasis, vol. 105, no. 5, pp. 908-919, 2011.

[29] J. Pink, S. Lane, M. Pirmohamed, and D. A. Hughes, "Dabigatran etexilate versus warfarin in management of non-valvular atrial fibrillation in UK context: quantitative benefit-harm and economic analyses," The Britich Medical Journal, vol. 343, no. 7830, Article ID d6333, 2011.

[30] A. R. Kansal, S. V. Sorensen, R. Gani et al., "Cost-effectiveness of dabigatran etexilate for the prevention of stroke and systemic embolism in UK patients with atrial fibrillation," Heart, vol. 98, no. 7, pp. 573-578, 2012.

[31] L. K. Langkilde, M. Bergholdt Asmussen, and M. Overgaard, "Cost-effectiveness of dabigatran etexilate for stroke prevention in non-valvular atrial fibrillation. Applying RE-LY to clinical practice in Denmark," Journal of Medical Economics, vol. 15, no. 4, pp. 695-703, 2012.

[32] T. Davidson, M. Husberg, M. Janzon, J. Oldgren, and L. A. Levin, "Cost-effectiveness of dabigatran compared with warfarin for patients with atrial fibrillation in Sweden," European Heart Journal, vol. 34, no. 3, pp. 177-183, 2013.
[33] L. Silva Miguel, E. Rocha, and J. Ferreira, "Economic evaluation of dabigatran for stroke prevention in patients with nonvalvular atrial fibrillation," Revista Portuguesa de Cardiologia, vol. 32, pp. 557-565, 2013.

[34] S. Lee, M. W. Anglade, D. Pham, R. Pisacane, J. Kluger, and C. I. Coleman, "Cost-effectiveness of Rivaroxaban compared to Warfarin for stroke prevention in atrial fibrillation," American Journal of Cardiology, vol. 110, no. 6, pp. 845-851, 2012.

[35] A. R. Harrington, E. P. Armstrong, P. E. Nolan Jr., and D. C. Malone, "Cost-effectiveness of apixaban, dabigatran, rivaroxaban, and warfarin for stroke prevention in atrial fibrillation," Stroke, vol. 44, no. 6, pp. 1676-1681, 2013.

[36] D. Coyle, K. Coyle, C. Cameron et al., "Cost-effectiveness of new oral anticoagulants compared with warfarin in preventing stroke and other cardiovascular events in patients with atrial fibrillation," Value in Health, vol. 16, no. 4, pp. 498-506, 2013.

[37] C. Rognoni, M. Marchetti, S. Quaglini, and N. L. Liberato, "Apixaban, dabigatran, and rivaroxaban versus warfarin for stroke prevention in non-valvular atrial fibrillation: a costeffectiveness analysis," Clinical Drug Investigation, vol. 34, no. 1, pp. 9-17, 2014.

[38] A. R. Kansal, M. Sharma, C. Bradley-Kennedy et al., "Dabigatran versus rivaroxaban for the prevention of stroke and systemic embolism in atrial fibrillation in Canada. Comparative efficacy and cost-effectiveness," Thrombosis and Haemostasis, vol. 108, no. 4, pp. 672-682, 2012.

[39] S. V. Sorensen, S. Peng, B. U. Monz, C. Bradley-Kennedy, and A. R. Kansal, "A comparative analysis of models used to evaluate the cost-effectiveness of dabigatran versus warfarin for the prevention of stroke in atrial fibrillation," PharmacoEconomics, vol. 31, no. 7, pp. 589-604, 2013.

[40] A. M. Chang, J. C. S. Ho, B. P. Yan, C. M. Yu, Y. Y. Lam, and V. W. Y. Lee, "Cost-effectiveness of dabigatran compared with warfarin for stroke prevention in patients with atrial fibrillationa real patient data analysis in a Hong Kong teaching hospital," Clinical Cardiology, vol. 36, no. 5, pp. 280-285, 2013.

[41] J. Harenberg, S. Marx, H.-C. Diener et al., "Comparison of efficacy and safety of dabigatran, rivaroxaban and apixaban in patients with atrial fibrillation using network meta-analysis," International Angiology, vol. 31, no. 4, pp. 330-339, 2012.

[42] B. L. Limone, W. L. Baker, J. Kluger, and C. I. Coleman, "Novel anticoagulants for stroke prevention in atrial fibrillation: a systematic review of cost-effectiveness models," PLoS ONE, vol. 8, no. 4, Article ID e62183, 2013.

[43] C. Claes, T. Mittendorf, M. Grond, and J.-M. Graf von der Schulenburg, "Inkrementelle Kosteneffektivität von Dipyridamol + Acetylsalicylsäure in der Sekundärprävention bei ischämischem nichtkardioembolischem Schlaganfall," Medizinische Klinik, vol. 103, pp. 778-787, 2009. 


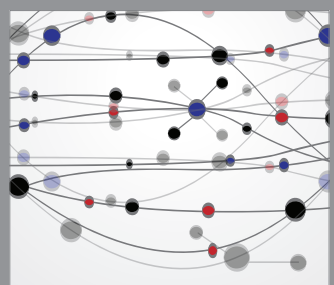

The Scientific World Journal
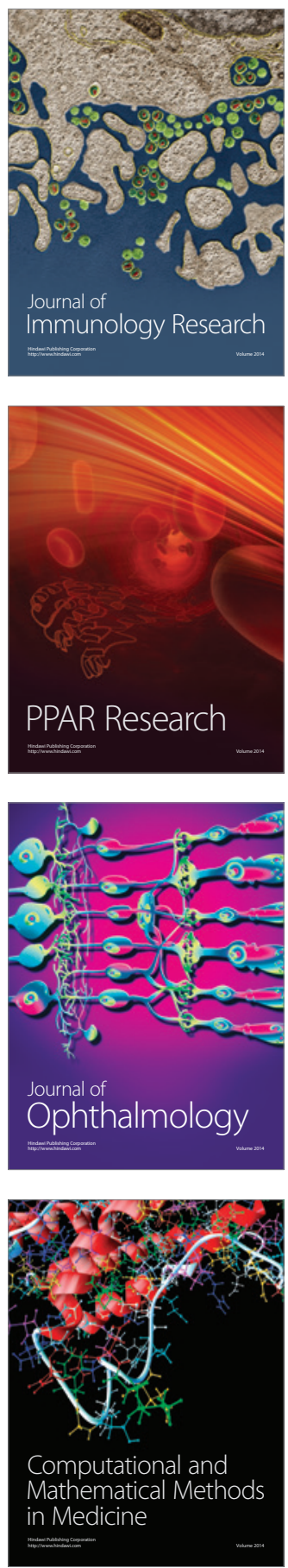

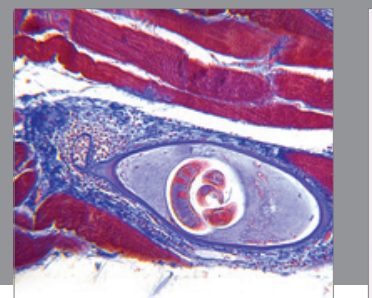

Gastroenterology

Research and Practice
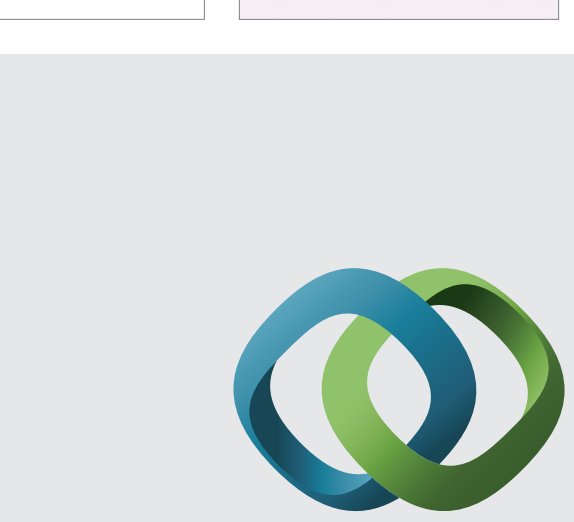

\section{Hindawi}

Submit your manuscripts at

http://www.hindawi.com
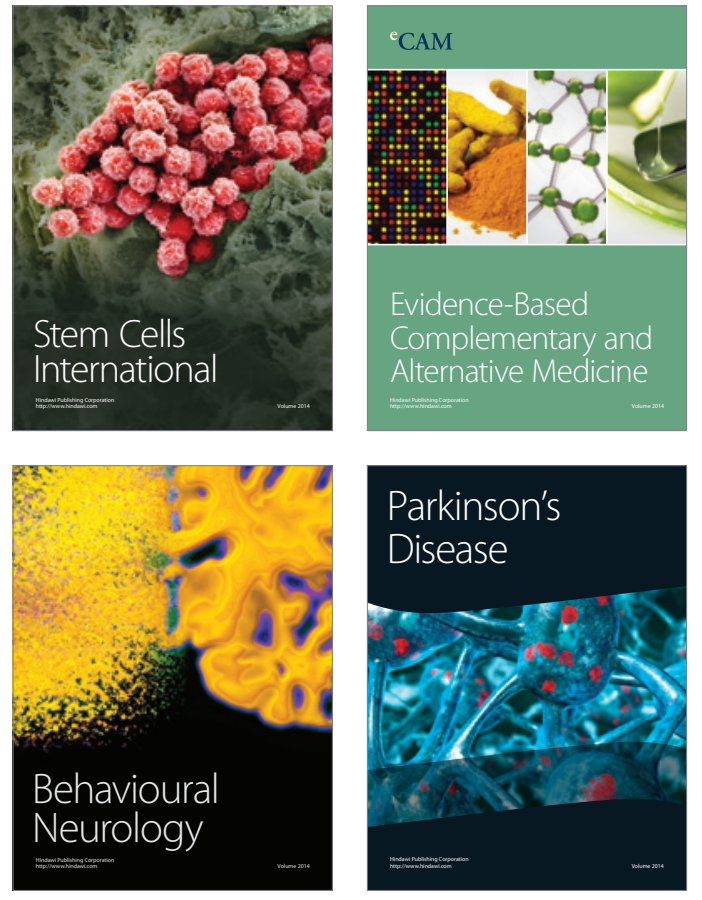
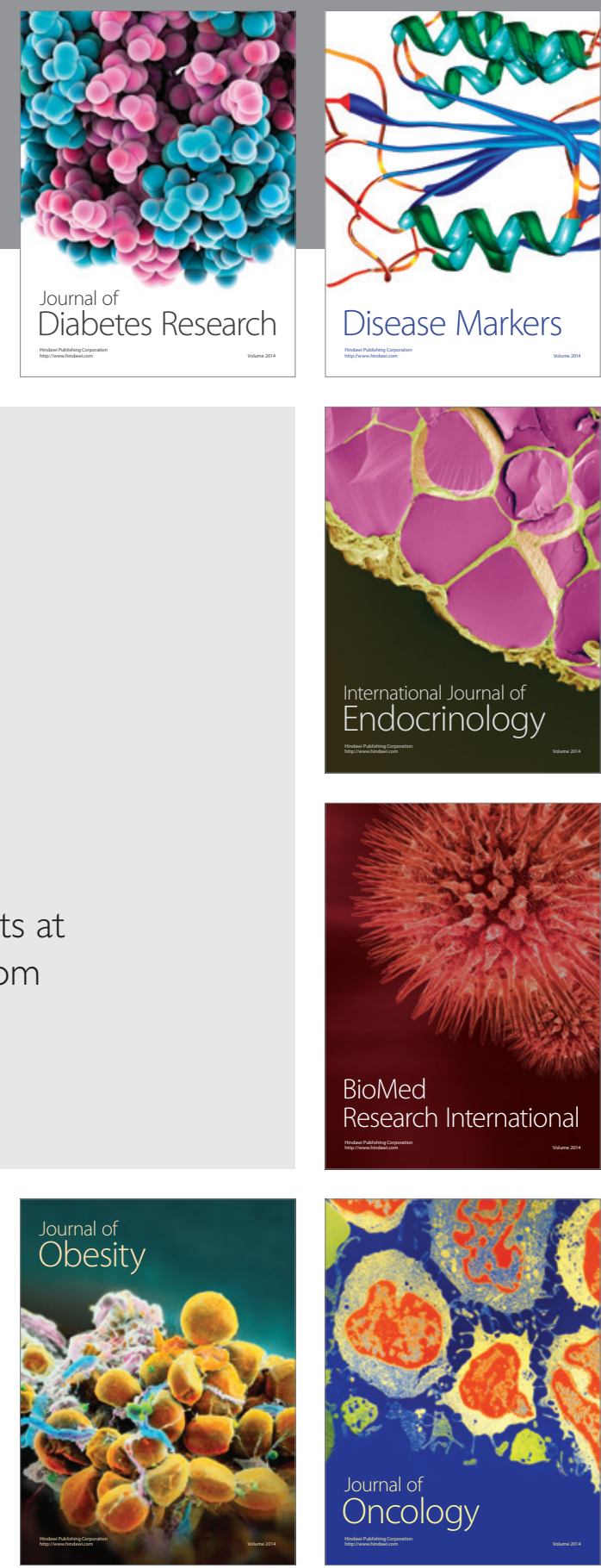

Disease Markers
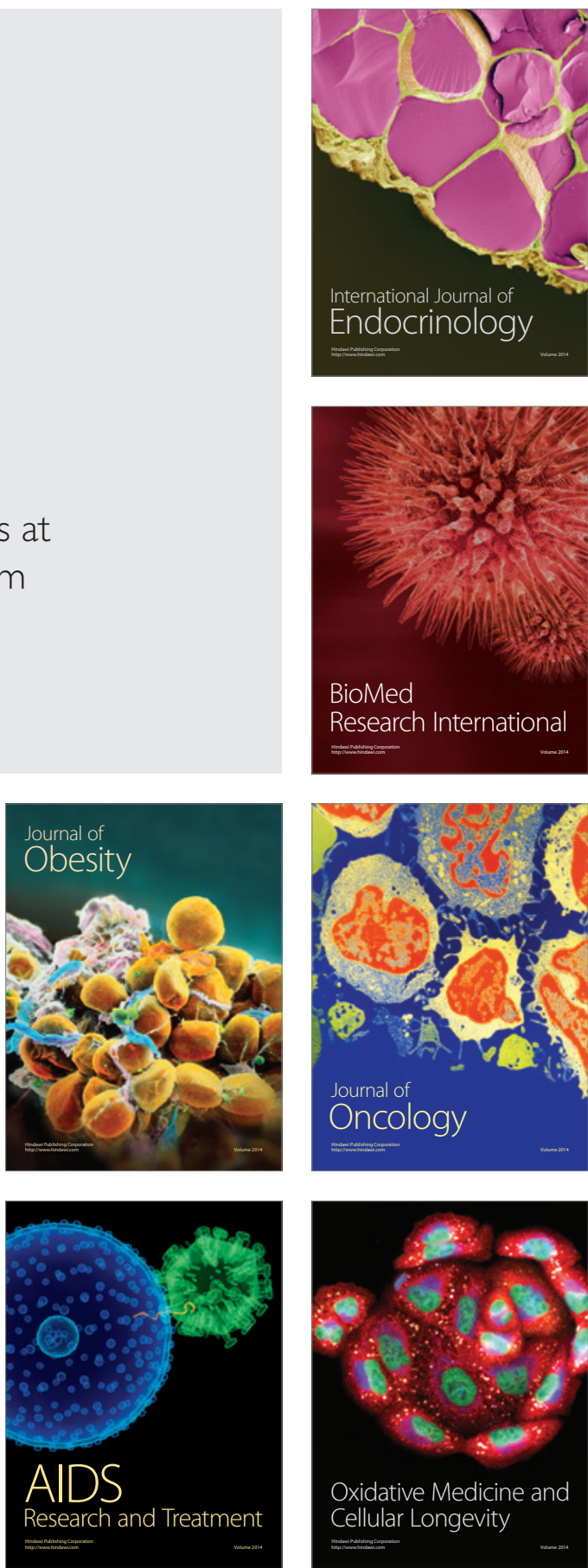